\title{
EVALUATION OF THE STABILITY AFTER ORTHODONTIC TREATMENT USING PAR INDEX
}

\author{
Chaitra Ramanathan
}

Charles University in Prague, Faculty of Medicine in Hradec Králové and University Hospital Hradec Králové, Czech Republic: Department of Dentistry

Summary: The aim of the present study is to establish the results using the scores obtained from the methodology that was applied for assessing the stability after 2 years post orthodontic treatment and stability in a sample of 69 individuals. After applying PAR index to the collected group of patients, a series of scores were obtained, which were then needed to be evaluated further to establish the results. The scores were evaluated using the nomogram. A comparison was done between the post treatment and the 2 years post treatment PAR weighting scores to determine if the results were stable after orthodontic treatment. The majority of the orthodontic patients were treated to a good standard and that the results appeared to be stable.

Key words: Orthodontic treatment; Stability; PAR index

\section{Introduction}

Stability acts as a good criterion, which is known to help in judging a successfully treated case. However the reality is found to be different that the treated cases relapse after a certain period of time. A question that is often raised regarding long-term stability results after orthodontic treatment in which length of period should give an appropriate estimate of stability. From the cost effectiveness point of view, a lifelong lasting effect of orthodontic therapy would be the preferred consequence. In some studies (3), it has been stated that expecting a high degree of stability after 20 years exceeds the usual expectations in the other fields of medicine and dentistry, other long term changes of the dentition due to growth, aging, periodontal diseases and caries as well as various types of dental restorations should be considered. Also studies have shown that an evaluation period of 10 years does justice to the nature of orthodontics $(18,19)$.

Although permanent retention is an option of achieving long-term stability, but as trained orthodontist it becomes duty to deal with the factors associated with the relapse and to aim in removing the relapse factors. These factors are to be taken into consideration and the retention phase of the patient should be planned so that the post treatment changes can be overcome to a large extent. The retention phase is defined as that phase of orthodontic treatment, which eliminates the factors causing relapse. It is defined by Moyers as "maintaining newly moved teeth in position long enough to aid in stabilizing their correction". The retention of teeth in ideal functional and esthetic position has always been a challenge to the orthodontist.

To determine the persistence of stability, the PAR index was used to assess the study casts of the collected group of 69 patients during the three different phases of the study. After which a series of scores were obtained, they were then evaluated using the nomogram. Studies have shown that the scores obtained can be plotted on the nomogram and accordingly results could be obtained $(1,2,4,5,6,8,14,15$, $16)$, which inturn helps in the evaluation of the overall quality of orthodontic treatment.

\section{Materials and Methods}

The study was retrospective in nature as it was done with the help of the study casts for the measurements of the occlusal traits before treatment, after immediate treatment and during the 2 years post treatment phase. During the selection of the sample for the study, the following criteria were considered:

1. The patient's co-operation and consent was necessary and after which the impressions were made in the post treatment phase.

2. The patients were required to belong to the group of more than or equal to 2 years of post treatment phase.

3. The sample of the study casts collected involved group of patients, who were treated by fixed appliances or by a combination of removable and fixed appliances. 
4. Further the study consisted of study casts, where treatment was done in both dental arches.

5. The study casts were considered to be intact without any broken margins.

Initially, the sample of patients were needed to be selected for assessing the stability after 2 or more years of orthodontic treatment from the Department of Dentistry in Hradec Králové. The study was done using the the PAR index. Approximately 90 patients were invited for the study, out of which 73 patients reported and agreed for the study. After completion of more than 2 years of orthodontic treatment, the decision was made for the impression of patients. The patients were between the age groups of 15-29 years. The male to female ratio was $18: 55$, indicating that a large number of patients were females, who received orthodontic treatment. The average time of completion of orthodontic treatment in these patients were more than two years as the treatment was completed in 2004 and they were in the period of retention after treatment during the year 2006 . Further, the study got limited to 69 patients because only 69 patients met all the required criteria for carrying out the study. After the collection of the sample, the scores were applied to each component of the dentition, i.e., to anterior segment both upper and lower arch, buccal segments on both right and left side, overjet, overbite and to the centerline. The scores were applied to the collected group ac- cording to the PAR index. Each score was known to depict the condition of the dentition. A score of zero indicates a good alignment, while higher score indicates a higher irregularity of the dentition. According to the PAR index, the difference between the score at the beginning and at the end of the treatment showed the degree of the improvement and the success of the orthodontic procedure.

The evaluation was done twice by the same clinician to reduce the risk of errors. The interval between the measurements was 6 weeks.

The pattern and sequence of assessment that was done for the different components of the dentition using the PAR index demostrates Tab. 1. Then the individual scores were multiplied by the weightings derived for the five components of the PAR index. For example: The upper and the lower anterior segments were multiplied by 1 , right and left buccal occlusion by 1 , overjet with 6 , overbite with 2 and centerline with 4 as shown in Tab. 2. This is done because of the fact that the PAR index components are weighted to balance the impact of the individual components of the overall result. After which the individual components with their weightings are summed up to establish the overall total as shown by Tab. 3 .

Similarly, after applying the PAR index to the three phases of the study, i.e. to the pre PAR weighting score, post PAR score weighting score and the 2 years post treat-

Tab. 1: The scores for each components of the dentition of pre treatment casts obtained on applying the PAR index.

\begin{tabular}{|c|c|c|c|c|c|c|c|}
\hline Patients & $\begin{array}{c}\text { Upper } \\
\text { anterior } \\
\text { segment }\end{array}$ & $\begin{array}{c}\text { Lower } \\
\text { anterior } \\
\text { segment }\end{array}$ & $\begin{array}{c}\text { Right } \\
\text { buccal } \\
\text { occlusion }\end{array}$ & $\begin{array}{c}\text { Left } \\
\text { buccal } \\
\text { occlusion }\end{array}$ & Overjet & Overbite & Centerline \\
\hline 1. & 4 & 2 & 0 & 0 & 1 & 0 & 1 \\
\hline 2. & 5 & 2 & 2 & 3 & 1 & 2 & 2 \\
\hline 3. & 4 & 1 & 3 & 3 & 1 & 1 & 2 \\
\hline 4. & 1 & 1 & 2 & 2 & 1 & 0 & 0 \\
\hline
\end{tabular}

Tab. 2: The scores with their respective weightings for all the 69 patients that are assessed before treatment.

\begin{tabular}{|c|c|c|c|c|c|c|c|}
\hline Patients & $\begin{array}{c}\text { Upper } \\
\text { score with } \\
\text { weightings }\end{array}$ & $\begin{array}{c}\text { Lower } \\
\text { score with } \\
\text { weightings }\end{array}$ & $\begin{array}{l}\text { Right buccal } \\
\text { relation with } \\
\text { weightings }\end{array}$ & $\begin{array}{c}\text { Left buccal } \\
\text { relation with } \\
\text { weightings }\end{array}$ & Overjet & Overbite & Centerline \\
\hline 1. & $4 \times 1$ & $2 \times 1$ & $0 \times 1$ & $0 \times 1$ & $1 \times 6$ & $0 \times 2$ & $1 \mathrm{X} 4$ \\
\hline 2. & $5 \times 1$ & $2 \times 1$ & $2 \times 1$ & $3 \times 1$ & $1 \mathrm{X} 6$ & $2 \times 2$ & $2 \times 4$ \\
\hline 3. & $4 \times 1$ & $1 \mathrm{X} 1$ & $3 \mathrm{X} 1$ & $3 \mathrm{X} 1$ & $1 \times 6$ & $1 \mathrm{X} 2$ & $2 \times 4$ \\
\hline 4. & $1 \mathrm{X} 1$ & $1 \mathrm{X} 1$ & $2 \times 1$ & $2 \times 1$ & $1 \times 6$ & $0 \times 2$ & $0 \times 4$ \\
\hline
\end{tabular}

Tab. 3: The scores with their overall total that is obtained by adding each of the components that were multiplied with its respective weightings.

\begin{tabular}{|c|c|}
\hline Patient & Overall total \\
\hline 1. & 16 \\
\hline 2. & 30 \\
\hline 3. & 27 \\
\hline 4. & 12 \\
\hline
\end{tabular}

Tab. 4: Total weightings in three phases of treatment.

\begin{tabular}{|c|c|c|c|}
\hline Patient & $\begin{array}{c}\text { Pre treatment } \\
\text { PAR weightings }\end{array}$ & $\begin{array}{c}\text { Post treatment } \\
\text { PAR weightings }\end{array}$ & $\begin{array}{c}\text { Post retention } \\
\text { PAR weightings }\end{array}$ \\
\hline 1. & 16 & 0 & 3 \\
\hline 2. & 30 & 3 & 4 \\
\hline 3. & 27 & 7 & 9 \\
\hline 4. & 12 & 0 & 0 \\
\hline
\end{tabular}


ment PAR weighting score, results described in the Tab. 9 were obtained.

This way the PAR index was applied for assessing the stability in the collected sample of 69 individuals.

\section{Results}

The scores obtained after applying the PAR index were subjected for assessment using the nomogram. The nomogram is one of the possible ways of detecting the improvement or the deterioration of the treatment and thereby helps in assessing the stability and quality of work.

In the study of asessing the improvement with the help of nomogram, the pre-treatment weighted PAR score was given on the horizontal ' $\mathrm{x}$ ' axis and the post-treatment weighted PAR score on the vertical ' $y$ ' axis. The pre-treatment and the post-treatment scores were read on their respective axis. Where the intercept falls, it indicates the degree of improvement which helps to provide three broad bands of treatment change, i.e.:

- worse - no different,

- improved,

- greatly improved.

Firstly the nomogram was plotted with the total PAR weightings of pretreatment on ' $\mathrm{x}$ ' axis with the scores starting from 0 to 40 with a difference of 5 between each reading, similarly the total PAR weightings of post treatment were plotted on ' $y$ ' axis with the scores starting from 0 to 30 with a difference of 5 between each reading. The following is represented with the Fig. 1. The graph helps in detection of improvement of the cases, i.e. it helps to know if the treatment was worse without any significant improvement, which could be referred to as worse - no different, or if there was a significant improvement, which could be re- ferred to as improved, or if there was a marked improvement, which could be referred as greatly improved, thus in this way the treatment results can be assessed using the nomogram.

The nomogram was obtained by placing the overall total of the patients that were obtained before and after treatment during the study. Thus we can see from the nomogram that:

1. No patients fell into the category of No different band of treatment change.

2. A large group of patients are in the range of 0 to 22 points, indicating that the cases fell into the category of Improved band of treatment change.

3. A fewer group of patients fell into the range of PAR score greater than 22 points, indicating that the cases fell into the category of Greatly improved band of treatment change.

The nomogram was plotted with the total PAR weightings after treatment on ' $\mathrm{x}$ ' axis and post treatment of more than 2 years on ' $y$ ' axis starting from 0 with a difference of 5 points on each axis as shown in Fig. 2. The nomogram was obtained by placing the overall total of the patients that were obtained after and during 2 years of post treatment phase of the study. Thus we can see from the nomogram that

1. Most of the patients fell into the first category of treatment change, indicating that the cases showed no significant variation during the post treatment phase of more than 2 years.

2. On the other hand, one point was evident in the second category of the change in treatment, indicating that the case was slightly deviating from the achieved result.

3. No patients fell into the third range of the treatment change, indicating that no case exhibited such a great deviation after treatment.

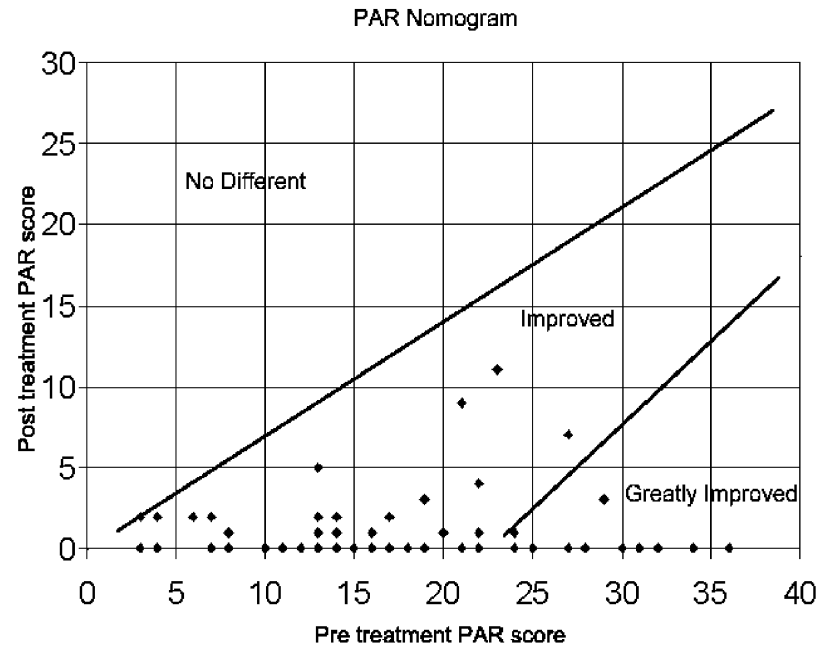

Fig. 1: Represents the PAR nomogram that has Pre treatment PAR score on the $\mathrm{x}$ axis and the Post treatment PAR score on the $y$ axis.
PAR Nomogram

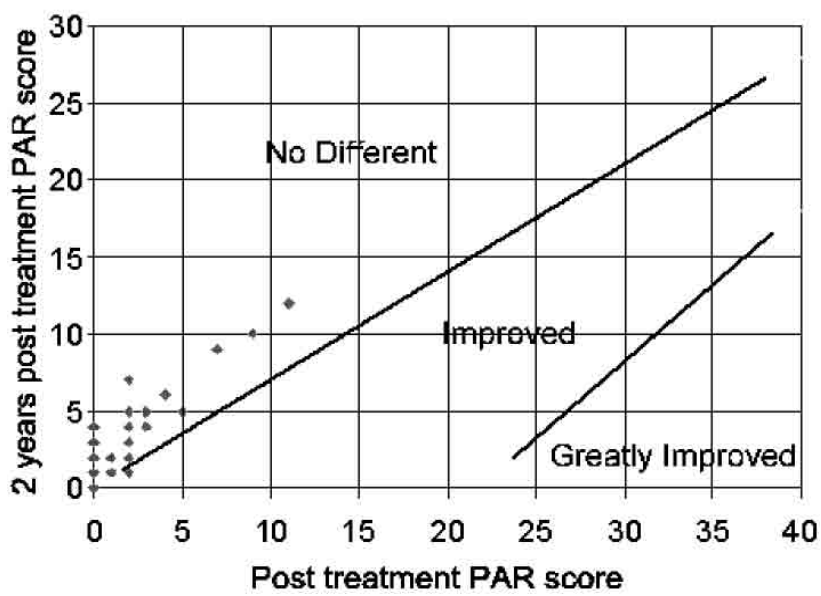

Fig. 2: Represents the PAR nomogram that has Post treatment PAR score on the $\mathrm{x}$ axis and 2 years post treatment PAR score on the $y$ axis. 


\section{Discussion}

PAR index was used for the study of assessing stability after orthodontic treatment in different phases i.e. before treatment, immediate after treatment and during post treatment phase of more than 2 years. No attempt was made to compare treatment results by different types of appliances. The study was mainly involved in a group of patients who were invited for the study and upon the consent of the patients and their parents. The study was started and it included patients with fixed appliance therapy or a combination of fixed and removable appliance therapy and the majority of the patients were females due to the fact that the ratio of male to female was 18:55 at the onset of the treatment, which gradually reduced to the ratio of 17:52, the reason being the inavailability of the criteria that was essential for the study. On assessing the study casts during each phase of the study, a set of scores were obtained that were then multiplied with their respective weightings and then the overall total was obtained. It was then plotted on the nomogram and assessed for the results. It was found that a large number of patients fell into the category of Improved and Greatly Improved range of improvement, which showed that the majority of the cases were treated to a very good level. Also when the post treatment and the post treatment phase of more than 2 years were compared, majority of the patients fell into the group of No different category of treatment indicating that the treatment results were stable and that it did not exhibit significant variations. For an institution as well as for a private practise such an analysis can contribute to quality assurance of treatment outcome over the years. The asessment also acts as an important tool in the process of total quality management of orthodontic care provision.

In this study, the improvement in PAR score at the post treatment stages can be explained to some extent by the treatment period, more recent the period the better quality was obtained in the results. Although it is known that the occlusal deterioration occurs in the period that follows orthodontic treatment, the dual arch fixed appliance treatment achieves and maintains the best post-treatment results (17). Also the stability of the results can be due to the fact that the patients were still in the retention phase of the treatment. PAR index helped in evaluating the study casts and thus is known to offer uniformity, objectivity and standardization in assessing the outcome of orthodontic treatment. However it needs to be revised in the light of new knowledge and the changing perceptions of standards and mainly to overcome the limitations that exist with the index. PAR index exhibits certain obvious limitations that must be considered when it is used in the evaluation of treatment outcomes, e.g., it cannot identify inappropriate arch expansion, inclination of incisors and improvement in appearance or psychosocial well being.

\section{Conclusions}

In this study, the relapse pattern was comparable for a group of patients treated orthodontically in the Department of Dentistry in Hradec Králové. When the study was made between the pre treatment and the post treatment phases, a majority of the patients of the group fell into the Improved or the Greatly improved range, indicating that the cases were treated to a good standard. On the other hand, when the study was compared for the stability of the result after more than 2 years of post treatment phase, it showed that the cases fell into the range of No different category indicating the cases appeared to be stable to a large extent. As a conclusion, it is possible to say that the majority of the cases were treated to a good standard and that the results appeared to be stable. However this can be supported by saying that the patients were in the retentive phase after treatment that helped in maintaining the results obtained. It is advisable to further carry out the study in order to detect the persistence of stability after few more years of treatment without the presence of retention appliance. More additional research in the field of indices becomes essential with time to provide the comparison of the results.

\section{References}

1. Afsharpanah A, Feghali R, Hans MG, Nelson S. Assessment of orthodontically untreated adolescents using the PAR index. J Dent Res 1996; 75 (AADR Abstract): 363 .

2. Afsharpanah A, Nelson S, Feghali R, Hans MG. Assessment of orthodontically untreated sample using the PAR index. J Dent. Res 1995; 74 (AADR Abstracts): 139.

3. Berg R, Fredlund A. Evaluation of orthodontic treatment results. Eur J Orthodont 1981; 3: 181-5.

4. DeGuzman L, Bahiraei D, Vig KWL, Vig PS, Weyant, RJ, O'Brien K. The validation of the Peer Assessment Rating index for malocclusion severity and treatment difficulty. Amer J Orthodont dentofacial Orthop 1995; 107: 172-6.

5. Fox NA. The first 100 cases: a personal audit of orthodontic treatment assessed by the PAR (Peer Assessment Rating) Index. Brit Dent J 1993; 174: 290-7.

6. Kerr WJS, Buchanan IB. Use of the PAR Index in Assessing the Effectiveness of Removable Orthodontic Appliances. Brit J Orthodont 1993; 20: 351-7.

7. O'Brien KD, Shaw WC, Roberts CT. The Use of Occlusal Indices in Assessing the Provision of Orthodontic Treatment by the Hospital Orthodontic Service of England and Wales. Brit J Orthodont 1993; 20: 25-35.

8. Otuyemi OD, Jones SR. Long-term evaluation of treated Class II Division 1 malocclusion utilizing the PAR index. Brit J Orthodont 1995; 22: 171-8.

9. Richmond S, O'Brien KD, Buchanan IB, Burden DJ. An introduction to Occlusal Indices, University of Manchester, Bradford, England, Ortho-Care (UK) Ltd. 1994.

10. Richmond S, Shaw WC, O’Brien KD, Buchanan IB, Jones R, Stephens CD, Roberts CT, Andrews M. The development of the PAR Index (Peer Assessment Rating): reliability and validity. Eur J Orthodont 1992; 14:125-39.

11. Richmond S, Shaw WC, Roberts CT, Andrews W. The PAR Index (Peer Assessment Rating): Methods to determine outcome of orthodontic treatment in terms of improvement and standards. Eur J Orthodont 1992; 14:180-7.

12. Richmond S, Andrews M. Orthodontic Treatment Standards in Norway. Eur J Orthodont 1993; 15: 7-15.

13. Richmond S, Shaw WC, Stephens CD, Roberts CT, Andrews M. Orthodontics in the General Dental services of England and Wales: A critical assessment of standards. Brit Dent J 1993; 174: 315-29.

14. Shaw WC, Richmond S, O'Brien KD. The use of occlusal indices: A European perspective. Amer J Orthodont dentofac Orthop 1995; 107: 1-10.

15. Shaw WC, Richmond S, O'Brien KD and Brook PH. Quality control in orthodontics: Indices of treatment need and treatment standards. Brit Dent J 1991; 170: $107-12$.

16. Spidlen M, Kotas M, Machytokova G, Gvuzdova K. Effectiveness of orthodontic treatment with removable and fixed appliances. Ortodoncie 2004; 4: 21-31. 
17. Spidlen M, Kotas M, Halirova M, Velka B, Novackova S. Treatment of Distal Occlusion Part I: Effectiveness. Ortodoncie 2006; 2: 18-28.

18. Summers C J. The occlusal index, a system for identifying and scoring occlusal disorders. Amer J Orthodont dentofac Orthop 1971; 59: 552-67.
19. Wijayaratne D, Harkness M, Herbison P. Functional appliance treatment assessed using the PAR index. Austr Orthodont J 2000; 16: 118-26.

20. Woods M, Lee D, Crawford E. Finishing occlusion, degree of stability and the PAR index. Austr Orthodont J 2000; 16: 9-15.

Submitted October 2006. Accepted December 2006.

\section{Corresponding author:}

Chaitra Ramanathan, BDS, University Hospital Hradec Králové, Department of Dentistry,

Sokolská 581, 50005 Hradec Králové, Czech Republic, e-mail: chaitra_ramanathan@yahoo.co.in 